\title{
High Dose Neutron Irradiation of Hi-Nicalon Type S Silicon Carbide Composites, Part 1: Microstructural Evaluations
}

\author{
Alejandro G. Perez-Bergquist ${ }^{1,2^{*}}$, Takashi Nozawa ${ }^{3}$, Chunghao Shih ${ }^{1}$, Keith J. Leonard ${ }^{1}$, \\ Lance L. Snead ${ }^{1}$, and Yutai Katoh ${ }^{1}$ \\ ${ }^{1}$ Oak Ridge National Laboratory, Oak Ridge, Tennessee, USA \\ ${ }^{2}$ University of Tennessee, Knoxville, Tennessee, USA \\ 3 Japan Atomic Energy Agency, Rokkasho, Aomori-ken, Japan
}

*Corresponding author address: Oak Ridge National Laboratory, PO Box 2008 MS6138, Oak Ridge TN, 37831-6138, USA. Tel.: 1-834-576-3252. E-mail: perezbergqag@ornl.gov.

\begin{abstract}
Over the past decade, significant progress has been made in the development of silicon carbide ( $\mathrm{SiC}$ ) composites, composed of near-stoichiometric $\mathrm{SiC}$ fibers embedded in a crystalline $\mathrm{SiC}$ matrix, to the point that such materials can now be considered nuclear grade. Recent neutron irradiation studies of Hi-Nicalon Type S SiC composites showed excellent radiation response at damage levels of 30-40 dpa at temperatures of $300-800^{\circ} \mathrm{C}$. However, more recent studies of these same fiber composites irradiated to damage levels of $>70 \mathrm{dpa}$ at similar temperatures showed a marked decrease in ultimate flexural strength, particularly at $300^{\circ} \mathrm{C}$. Here, electron microscopy is used to analyze the microstructural evolution of these irradiated composites in order to investigate the cause of the degradation. While minimal changes were observed in Hi-Nicalon Type S SiC composites irradiated at $800^{\circ} \mathrm{C}$, substantial microstructural evolution is observed in those irradiated at $300^{\circ} \mathrm{C}$. Specifically, carbonaceous particles in the fibers grew by $25 \%$ compared to the virgin case, and severe cracking occurred at interphase layers.
\end{abstract}

\section{Introduction}

Continuous SiC fiber-reinforced SiC matrix composites have been considered promising structural materials for high temperature applications for decades, owing to their outstanding strength at high temperature, chemical inertness, low coefficient of thermal expansion, and added toughness and reliability derived by compositization [1-3]. For fusion energy applications, $\mathrm{SiC}$ composites are of particular interest due to their high radiation tolerance at elevated temperature, their low activation and decay heat properties, and their low tritium permeability [4-8].

While monolithic $\mathrm{SiC}$ has some applications in fusion, it fails as a structural material due to its inherent brittle nature. However, the implementation of small diameter SiC fibers into $\mathrm{SiC}$ composite systems has resulted in the development of $\mathrm{SiC} / \mathrm{SiC}$ composites with more advantageous strength reliability and damage tolerance properties [9]. SiC/SiC composites consist of a continuous or dispersed fiber phase, a continuous matrix phase, and an interface layer or layers between the two, known as the interphase. For the fiber phase, two low-oxygen, slightly carbon-rich, near-stoichiometric SiC fibers have been developed: Hi-Nicalon Type S and Tyranno SA. Both fibers exhibit stability under high levels of neutron irradiation, and both are commercially available [1]. Pyrolytic carbon $(\mathrm{PyC})$, usually deposited by chemical vapor deposition (CVD), is used as the interphase. 
Fracture properties of the composite may be tailored by adjusting the thickness or a compliant interphase layer: either a single PyC layer, or some number of multiple layers of alternating $\mathrm{PyC}$ and $\mathrm{SiC}$. SiC fibers are then woven and infiltrated within a polycrystalline $\mathrm{SiC}$ matrix. The current nuclear grade composites are infiltrated through either chemical vapor infiltration (CVI) or nano-infiltration and transient eutectic-phase (NITE) processes, which have been shown to exhibit good dimensional stability and strength characteristics in response to neutron irradiation [1].

Numerous studies have been performed on the neutron irradiation behavior of $\mathrm{SiC} / \mathrm{SiC}$ composites [1, 2, 10-17]. In general, these nuclear-grade composites have demonstrated outstanding radiation resistance, showing minor or no degradation in proportional limit stress and ultimate strength after neutron irradiation doses exceeding $40 \mathrm{dpa}$ at $800^{\circ} \mathrm{C}$ [9]. However, detailed mechanical property examinations of Hi-Nicalon Type S SiC composites have shown substantial degradation in ultimate flexural strength at dose levels of about $70 \mathrm{dpa}$ at lower irradiation temperatures $\left(\sim 300^{\circ} \mathrm{C}\right)$. Specifically, after irradiation to $70 \mathrm{dpa}$, strengths dropped from $335 \mathrm{MPa}$ in the unirradiated state to 205 $\mathrm{MPa}$ at $800^{\circ} \mathrm{C}, 200 \mathrm{MPa}$ at $500^{\circ} \mathrm{C}$, and $95 \mathrm{MPa}$ at $300^{\circ} \mathrm{C}$ [18]. Similarly, average proportional limit stress was measured at $181 \mathrm{MPa}$ in the unirradiated state. The proportional limit stress did not change after irradiation at $800^{\circ} \mathrm{C}$ but dropped to $128 \mathrm{MPa}$ at $500^{\circ} \mathrm{C}$ and 91 $\mathrm{MPa}$ at $300^{\circ} \mathrm{C}$ [18]. In this work, scanning and transmission electron microscopy is used to investigate the microstructural evolution of Hi-Nicalon Type S composites after irradiation to very high dose at temperatures of 800,500 , and $300^{\circ} \mathrm{C}$.

\section{Experimental Procedures}

Hi-Nicalon Type S near-stoichiometric SiC fibers (Nippon Carbon, Tokyo, Japan) were used in this study. A $0^{\circ} / 90^{\circ}$ stack of two-dimensional satin weave fabrics of these fibers was coated via CVD with five thin layers of PyC ( $\sim 20 \mathrm{~nm}$ thickness) and four layers of $\mathrm{SiC}(\sim 200 \mathrm{~nm}$ in thickness) to create a multilayer interphase, followed by deposition of a polycrystalline $\beta$-phase $\mathrm{SiC}$ matrix using a CVI process [19].

Flexural beam test specimens machined from the CVI composite panel were neutron irradiated within the flux trap of the High Flux Isotope Reactor (HFIR) at Oak Ridge National Laboratory to levels of $\sim 71, \sim 74$, and $\sim 71$ dpa $\left(1 \mathrm{dpa} \approx 1 \times 10^{25} \mathrm{n} / \mathrm{m}^{2}, \mathrm{E}>0.1\right.$ $\mathrm{MeV}$ ) at temperatures of 800,500 , and $300^{\circ} \mathrm{C}$, respectively. The irradiated specimens were cut with a diamond saw and polished using a Buehler Minimet 1000 Polisher for microstructural analysis in a Hitachi S4700 scanning electron microscope (SEM).

Transmission electron microscope (TEM) foils were fabricated from the irradiated samples via the use of an FEI Quanta Dual-beam combination focused ion beam (FIB) and SEM. Samples were fabricated so as to capture regions containing the SiC fiber, interphase, and matrix. TEM foils were analyzed in a Phillips CM 200 analytical TEM operating at 200 $\mathrm{kV}$ using the techniques of bright field (BF) imaging, selected area electron diffraction (SAED), high resolution TEM (HRTEM), x-ray energy dispersive spectroscopy (EDS) performed in scanning TEM (STEM) mode, high angle annular dark field (HAADF) imaging, and electron energy loss spectroscopy (EELS).

\section{Results and Discussion}

TEM was first performed on an unirradiated $\mathrm{SiC} / \mathrm{SiC}$ composite sample to provide a comparison for the irradiated specimens. The Hi-Nicalon Type S fiber is comprised of SiC 
grains with some free carbon, generally containing a turbostratic texture, located between $\mathrm{SiC}$ grains [20]. Previous studies have shown that the fiber microstructures display virtually no evolution from temperature alone up to $\sim 1600^{\circ} \mathrm{C}$. Further behavior of unirradiated Hi-Nicalon Type S fiber behavior is available in the literature [21]. The composite system we tested is shown in Figure 1. Part of the $\sim 11 \mu \mathrm{m}$ diameter fiber is shown, coated with a thin layer of PyC of $\sim 20 \mathrm{~nm}$ in thickness. Four iterative bilayers of SiC ( $\sim 200 \mathrm{~nm}$ in thickness) and PyC ( $\sim 20 \mathrm{~nm}$ in thickness) stack upon the initial PyC layer, and CVI-deposited SiC grains compose the matrix. SiC and PyC layers are both uniform in size and are free from the presence of voids or cracks at interfaces.

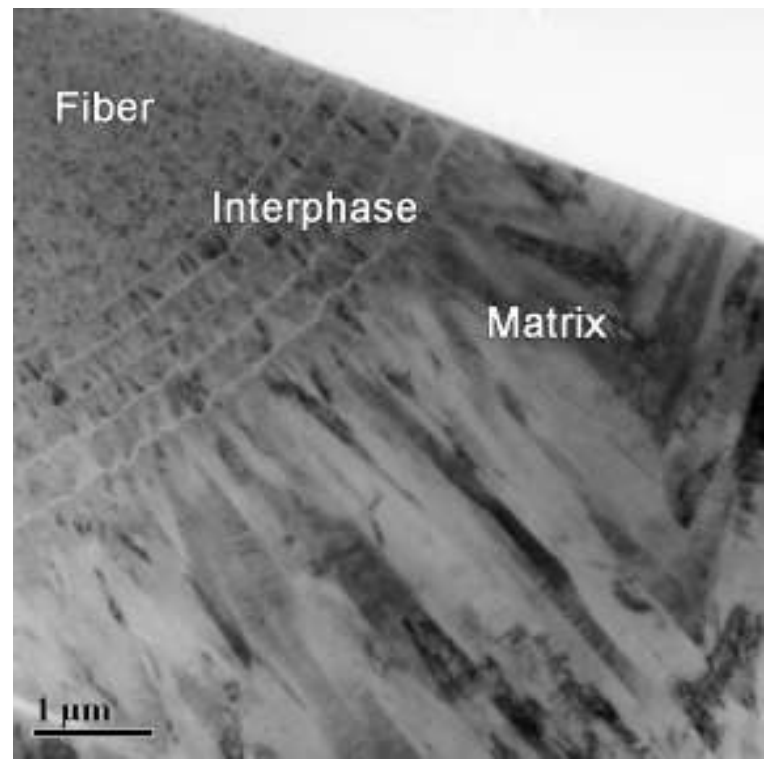

Figure 1. BF TEM image showing part of an unirradiated SiC fiber, surrounded by interphase layers and CVI-deposited SiC matrix.

Figure 2 shows SAED patterns from the unirradiated and irradiated fibers, showing no phase change in the fiber as a result of irradiation. The circular ring pattern is indicative of nanostructured material, and indexing of the rings reveals a consistent 3C SiC polytype. The lack of a diffuse halo in the figure, as well as minimal ring broadening, indicates a lack of amorphization as a result of irradiation. Figure 3 shows BF TEM images of the unirradiated fiber core and irradiated fiber cores at temperatures of 300,500 , and $800^{\circ} \mathrm{C}$, respectively (Figure 3a-d). Images are all shown such that sample thickness approaches zero at the top left corner and increases towards the bottom right corner. Regions shown in the top left of the images have been damaged from the FIB sample preparation process and thus were not used for SAED or HRTEM measurements. The unirradiated fiber is composed of small SiC grains of roughly 20 to $60 \mathrm{~nm}$ in diameter, interspersed with irregularlyshaped secondary phase particles of anywhere from about 5 to $40 \mathrm{~nm}$ in size. HRTEM revealed the secondary phase regions to be solid (not void area) and lacking in crystalline order both before and after irradiation (Figure 3e), and EDS performed in STEM mode showed the secondary phases to be carbon-rich. Previous papers have reported these pockets to be comprised of turbostratic carbon in the unirradiated condition [21]. A high 
angle annular dark field image of the fiber irradiated at $300^{\circ} \mathrm{C}$, showing the secondary phase regions to be composed of lower- $\mathrm{Z}$ material than $\mathrm{SiC}$, is provided in Figure $3 \mathrm{f}$.

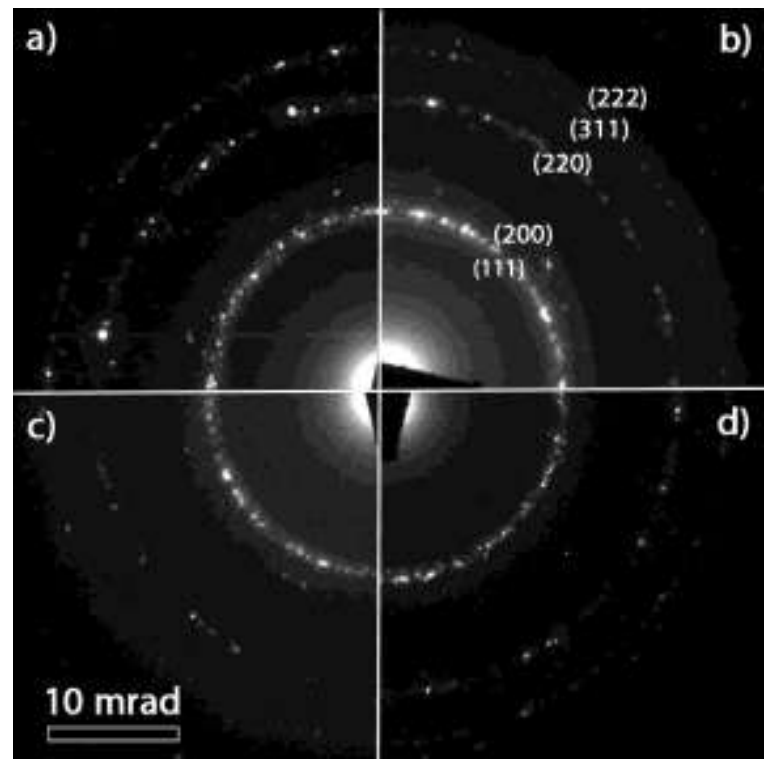

Figure 2. Diffraction patterns from the a) unirradiated fiber and from the fibers irradiated at b) $300^{\circ} \mathrm{C}$, c) $500^{\circ} \mathrm{C}$, and d) $800^{\circ} \mathrm{C}$, showing no phase shift due to irradiation.
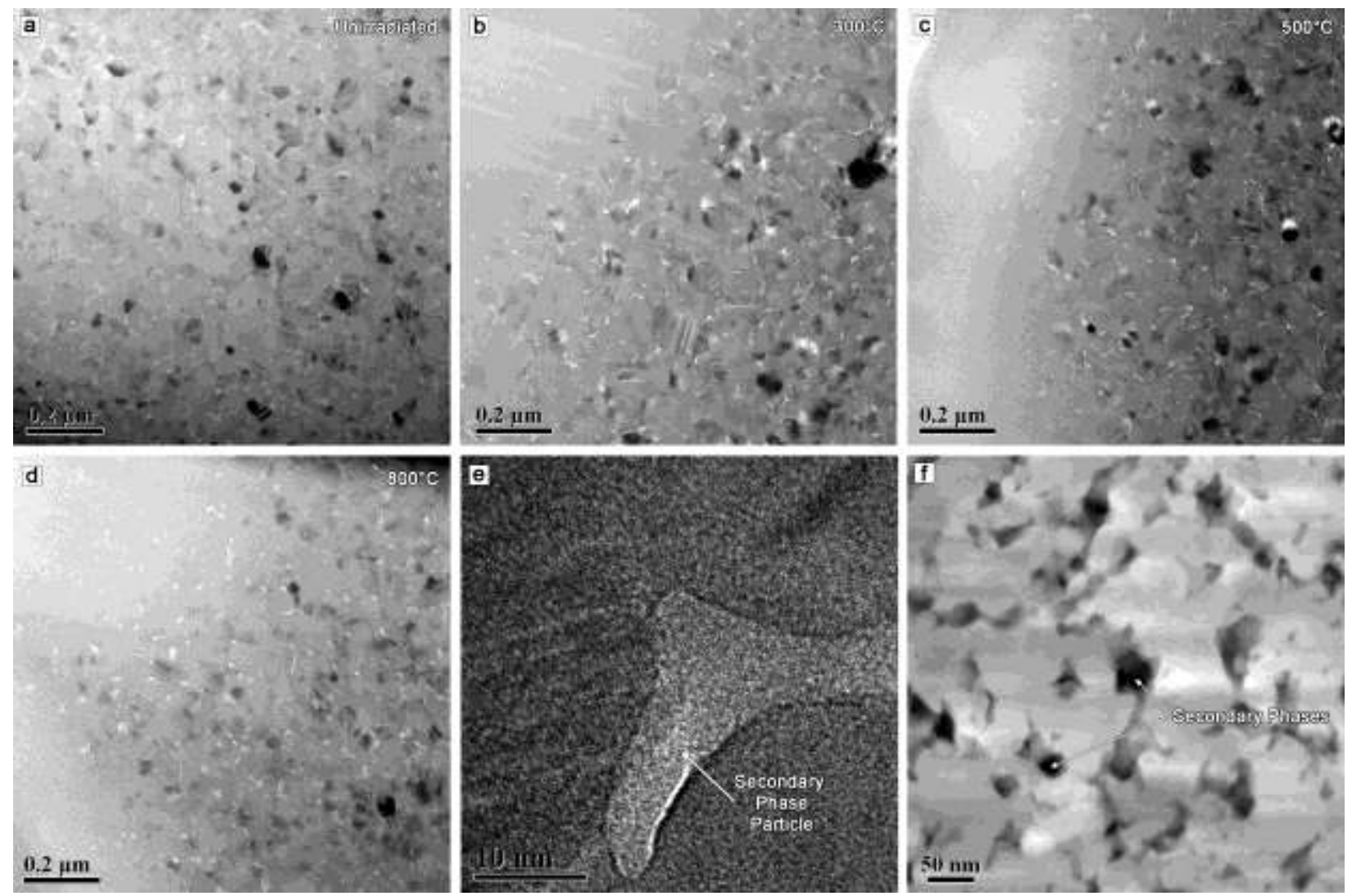

Figure 3. TEM images of the a) unirradiated fiber interior and irradiated fiber interiors at b) $300^{\circ} \mathrm{C}$, c) $500^{\circ} \mathrm{C}$, and d) $800^{\circ} \mathrm{C}$. Film thickness approaches zero at top left corners. All 
fibers display reasonably similar size, distribution, and density of secondary phases. e) HRTEM image of a selected secondary phase particle after irradiation at $300^{\circ} \mathrm{C}$ showing a lack of crystallinity. f) HAADF image of the fiber irradiated at $300^{\circ} \mathrm{C}$, with dark regions representing secondary phases.

Size measurements of the secondary phase particles were made manually by drawing a line across the farthest two points of a particle, bisecting that line with a perpendicular line across the width of the particle, and averaging the two values to produce an average particle diameter. A minimum of one hundred particles was measured for each irradiated sample. Results of the measurements are shown in Table 1. The unirradiated fiber exhibited an average particle diameter of $14.8 \mathrm{~nm}$, with a standard deviation of $5.9 \mathrm{~nm}$. Analysis of the irradiated fibers indicated a slight increase in the secondary phase particle size with decreasing irradiation temperature, with samples irradiated at 800,500 , and $300^{\circ} \mathrm{C}$ displaying average particle diameters of $14.0,15.4$, and $18.5 \mathrm{~nm}$, respectively. However, data set variance was substantial, as data sets had standard deviations of 5.4, 7.2, and $8.4 \mathrm{~nm}$.

Given the standard deviations of the data sets, it is difficult to definitively conclude that significant changes are occurring in the size of the secondary phase particles from average particle diameters alone. However, organizing the data into histograms, as displayed in Figure 4, gives further credence to the idea that secondary phase particles are indeed growing under low-temperature irradiation. As seen in Figure 4, the most number of particles in the unirradiated fiber reside within the $10-15 \mathrm{~nm}$ bin, with very few particles reaching sizes of over $30 \mathrm{~nm}$. The same trends hold true at $800^{\circ} \mathrm{C}$. At $500^{\circ} \mathrm{C}$, while the 10 $15 \mathrm{~nm}$ bin still holds the most number of particles, the number of large particles over 30 $\mathrm{nm}$ in size starts to increase. At $300^{\circ} \mathrm{C}$, the most populated bin shifts to the $15-20 \mathrm{~nm}$ range, with large numbers of particles over $30 \mathrm{~nm}$ in size appearing as well. Combined with the average particle sizes, the histogram data would certainly seem to suggest growth of the secondary phase, carbonaceous particles in Hi-Nicalon Type S SiC fibers under low temperature, high dose neutron irradiation, something that was not observed in $\mathrm{SiC}$ fibers irradiated at much lower doses [19].

Table 1. Size data for secondary phase particles in virgin and irradiated $\mathrm{SiC}$ fibers.

\begin{tabular}{ccccc}
\hline & Virgin & $300^{\circ} \mathrm{C}$ & $500^{\circ} \mathrm{C}$ & $800^{\circ} \mathrm{C}$ \\
\hline Average Particle Diameter $(\mathrm{nm}):$ & 14.8 & 18.5 & 15.4 & 14.0 \\
Median Particle Diameter $(\mathrm{nm}):$ & 13.9 & 18.3 & 13.9 & 12.8 \\
Standard Deviation $(\mathrm{nm}):$ & 5.9 & 8.4 & 7.2 & 5.4 \\
\hline
\end{tabular}




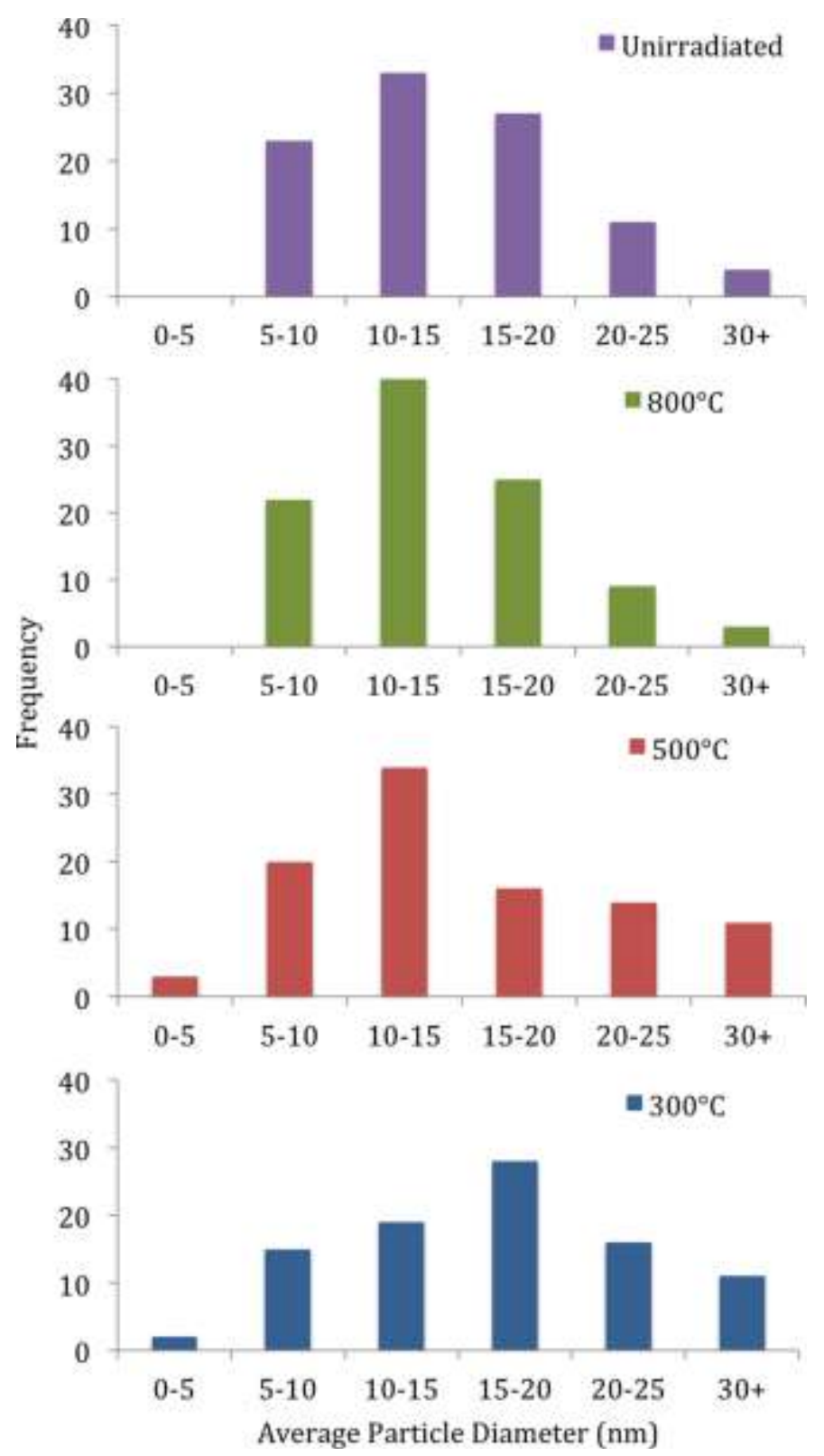

Figure 4. Histograms of the secondary phase particles in the unirradiated fiber and the fibers irradiated at 300,500 , and $800^{\circ} \mathrm{C}$. Each histogram displays data for 100 particles.

While changes in TEM sample thickness made quantitative measurements difficult, qualitative perusal of the virgin and irradiated fiber regions did not seem to reveal any substantial changes in either the density or distribution of the secondary phase particles between samples. Visible irradiation damage in the fibers also seemed to be minimal. At the given irradiation levels, only black-spot damage or small dislocations loops would be expected to be found in neutron-irradiated SiC fibers [18], but even black-spot damage was found to be negligible after tilting to varying diffraction conditions in the TEM. Overall, BF TEM imagery and SAED analysis showed very limited differences between the irradiated and unirradiated $\mathrm{SiC}$ fibers, with the subtle change in carbonaceous particle size in the fibers irradiated at low temperature being the primary point of interest. 
The reason for the growth of the carbonaceous particles could be due to irradiation induced swelling of said structures. Swelling of $\mathrm{SiC}$ has been well established in the literature with total swelling saturating quickly with irradiation dose. Swelling rates are in the $2-3 \%$ range at low temperature then drop to about $0.2 \%$ at around $1000^{\circ} \mathrm{C}$ before rising again to over $1 \%$ at $1600^{\circ} \mathrm{C}$ [22]. The swelling behavior of graphite, turbostratic carbon, and other carbon forms has not been quite so thoroughly examined, however. In graphite, swelling is actually negative for moderate neutron irradiation doses in the range of $400-900^{\circ} \mathrm{C}[23,24]$, but extrapolation of published data indicates that graphite swelling should be positive for high dose, low temperature irradiations such as the $300^{\circ} \mathrm{C}$ test discussed here. Similarly, swelling has been observed in pyrolytic carbon with a turbostratic structure [25].

Swelling of the carbonaceous pockets would result in undue stresses being applied to surrounding $\mathrm{SiC}$ grains. If the stresses were significant enough, they could lead to or assist in grain boundary failure within the fiber. Significant swelling could also lead to loss of structural integrity of the carbonaceous pockets. Both of these things in turn could help explain the observed irradiation-induced strength degradation of the fiber composites. However, no grain boundary cracking was observed at any tested temperature in these experiments, and HRTEM work did not reveal distinctions between the structures of the pockets in the samples tested at different temperatures.

In contrast to the relatively minor changes observed in the SiC fibers, in the evaluation of the interphase region we found a notable shift in the behavior of the irradiated specimens at different temperatures, as shown in Figure 5. Figure 5a shows an SEM micrograph of the polished surface of one of the unirradiated sets of fiber composites. The surface appeared smooth and clean, including at the interphase regions. Figure $5 \mathrm{~d}$, displaying the irradiated sample at $800^{\circ} \mathrm{C}$, looks remarkably similar, with clean, smooth transitions between the fiber, interphase, and matrix regions. The sample irradiated at $500^{\circ} \mathrm{C}$, however, exhibited some noticeable polishing damage at the fiber/interphase/matrix interfaces (Figure $5 \mathrm{c}$ ), while the sample irradiated at $300^{\circ} \mathrm{C}$ showed severe cracking and degradation at the interphase (Figure $5 \mathrm{~b}$ ). 

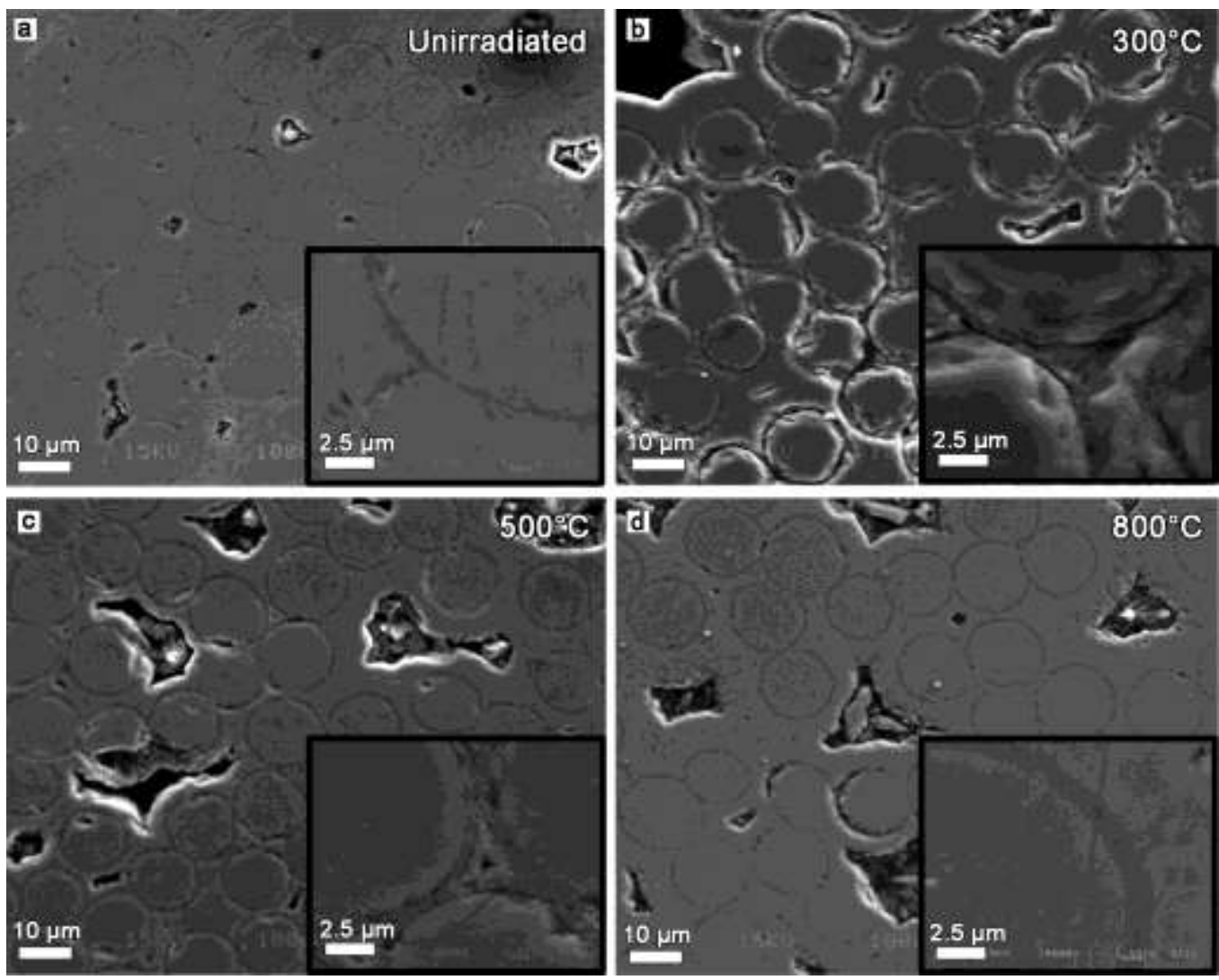

Figure 5. SEM images of a) unirradiated fibers and fibers irradiated at b) $\left.300^{\circ} \mathrm{C}, \mathrm{c}\right) 500^{\circ} \mathrm{C}$, and d) $800^{\circ} \mathrm{C}$. Degradation of interphase layers is more pronounced at lower temperatures.

Further investigation of the interphase regions via BF TEM showed similar results. In Figure 6a, the unirradiated interphase region is shown, while the interphase regions for the samples irradiated at 300,500 , and $800^{\circ} \mathrm{C}$ are shown in Figures $6 \mathrm{~b}-\mathrm{d}$. Similar to the unirradiated specimen, the sample irradiated at $800^{\circ} \mathrm{C}$ contained four uniform $\mathrm{SiC}$ interphase layers separated by uniform PyC layers, with no visible deterioration of any of the deposited films. SiC layers measured about $125 \mathrm{~nm}$ thick, while PyC layers measured about $20 \mathrm{~nm}$ thick. In the sample irradiated at $500^{\circ} \mathrm{C}$, only the innermost three $\mathrm{SiC}$ layers remained relatively uniform while the outermost layer had decomposed into discontinuous segments. SiC layers were slightly thinner on average, with a thickness of about $105 \mathrm{~nm}$, while PyC layers remained relatively consistent at about $20 \mathrm{~nm}$. Portions of the outermost, partially-decomposed $\mathrm{SiC}$ layer measured up to $140 \mathrm{~nm}$ thick. 

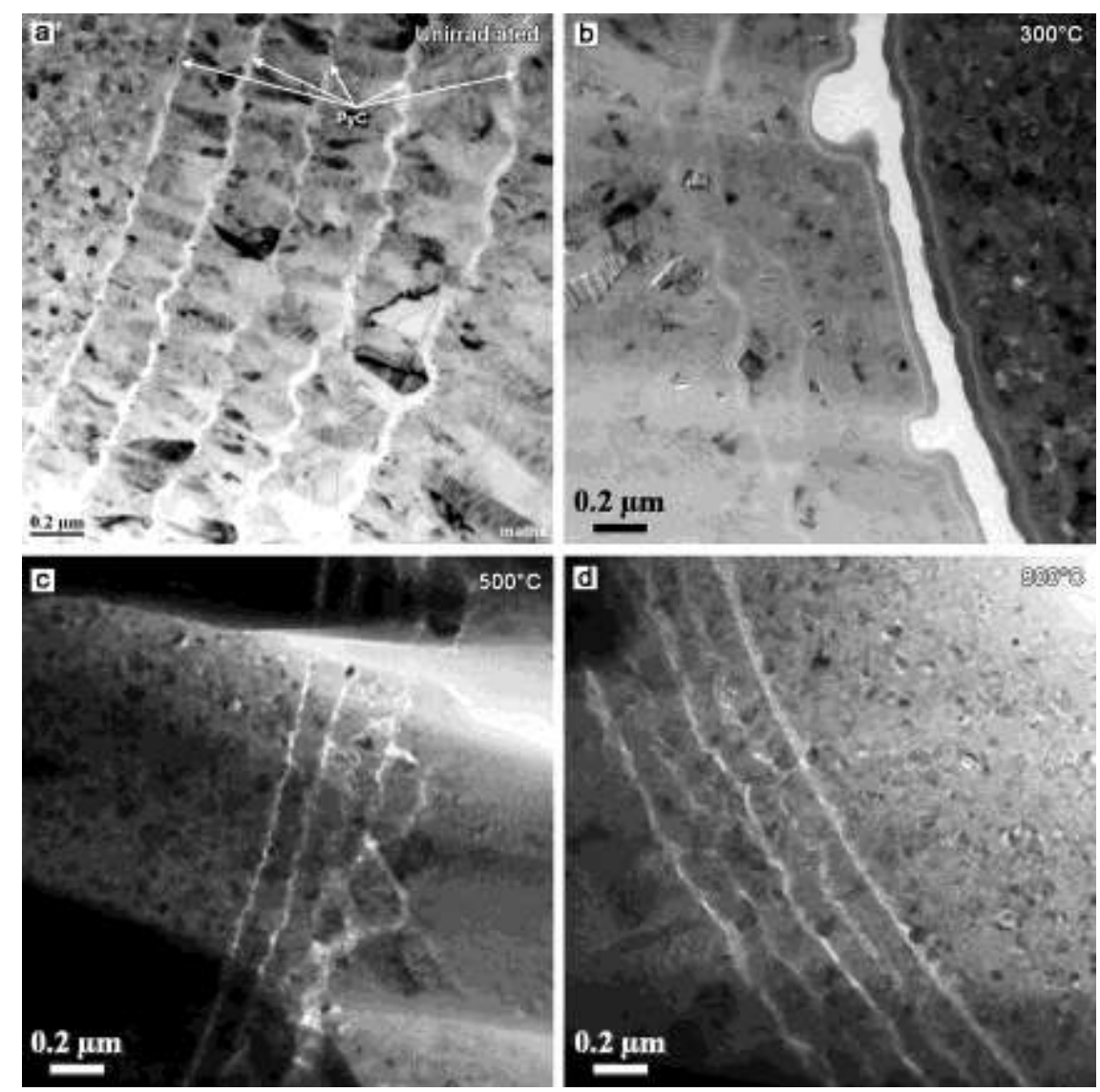

Figure 6. BF TEM images of the interphase regions from the a) unirradiated sample and irradiated samples at b) $300^{\circ} \mathrm{C}$, c) $500^{\circ} \mathrm{C}$, and d) $800^{\circ} \mathrm{C}$. The sample irradiated at $300^{\circ} \mathrm{C}$ shows the greatest deterioration in the interphase, with a large gap present at the innermost PyC/SiC interface. Dark regions in c) and d) are artifacts from the FIB thinning procedure.

The most drastic differences in interphase morphology, however, were seen in the $300^{\circ} \mathrm{C}$ sample. As reported earlier, initial SiC layer thicknesses were measured at about 200 $\mathrm{nm}$. In the sample irradiated at $800^{\circ} \mathrm{C}$, average $\mathrm{SiC}$ layer thickness was measured at 125 $\mathrm{nm}$, while the layer thickness was measured at $105 \mathrm{~nm}$ in the sample irradiated at $500^{\circ} \mathrm{C}$. A further drop in thickness was observed in the sample irradiated at $300^{\circ} \mathrm{C}$, which exhibited continuous, crystalline layers with a thickness of just $80 \mathrm{~nm}$. While there is statistical uncertainty involved in the measurement of these layers due to limited sampling within the TEM, the data nonetheless indicates a significant drop in SiC layer thickness after irradiation, with an inverse correlation between SiC layer thickness and temperature.

In addition, the layers in the $300^{\circ} \mathrm{C}$ sample were substantially more irregular than in the other specimens, and as in the $500^{\circ} \mathrm{C}$ sample, the outermost layer was observed to have decomposed into thick, discontinuous segments, some of which measured up to $150 \mathrm{~nm}$ thick. Perhaps the most stark difference visible in the $300^{\circ} \mathrm{C}$ sample was in the morphology of the layers that had previously consisted solely of PyC. For one, these layers increased in thickness, up to an average of about $40 \mathrm{~nm}$ with select regions approaching $70 \mathrm{~nm}$. In addition, HRTEM of the SiC/formerly-PyC layer interfaces did not show the characteristic, turbostratic graphite texture of PyC [26], but instead showed fully amorphous contrast, 
indicating that the layers may have transformed from PyC to an amorphous mixture of both carbon and $\mathrm{SiC}$, as evidenced by the decrease in the polycrystalline $\mathrm{SiC}$ layer thicknesses. HRTEM images of the SiC/PyC layer interface in the unirradiated condition and the $\mathrm{SiC} /$ formerly-PyC layer interface after irradiation at $300^{\circ} \mathrm{C}$ are shown in Figure 7.
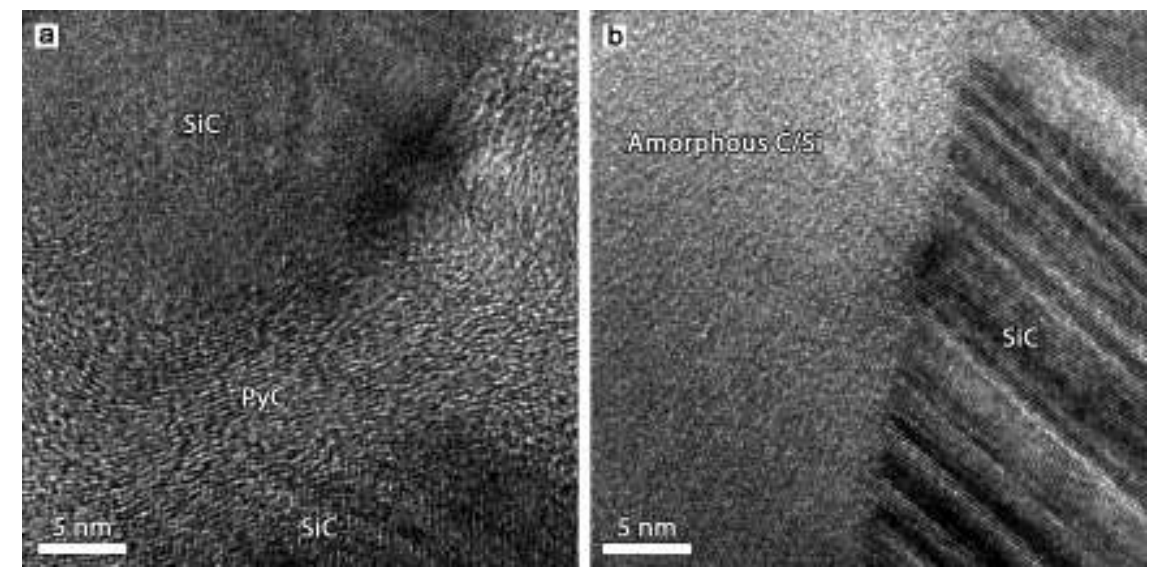

Figure 7. HRTEM images of a) $\mathrm{SiC}$ and PyC layers in the unirradiated specimen and b) the $\mathrm{SiC} /$ formerly-PyC layer interface in the sample irradiated at $300^{\circ} \mathrm{C}$. Notice that the turbostratic texture of the $\mathrm{PyC}$ becomes fully amorphous after high dose irradiation at this temperature.

In addition, a large gap of about $100 \mathrm{~nm}$ in thickness developed between the fiber and innermost $\mathrm{SiC}$ layer, seemingly bifurcating the innermost amorphous carbon layer, and large, void-like openings (visible in Figure 5b, likely artifacts of sample preparation process) punctuated the gap. A region of slightly darker contrast existed at the gap interface, which EDS revealed to be due to a Ga-rich layer at the outer edge of the amorphous carbon (also due to sample fabrication). Given that the gap was found to be present before final sample thinning, as well as the fact that such a gap was not found in the unirradiated sample or the samples irradiated at 500 and $800^{\circ} \mathrm{C}$, we do not believe the gap to be an artifact of the sample preparation process, although its magnitude may have been exacerbated by said process.

Additional TEM analysis of the matrix regions revealed dense, pore-free material with limited irradiation damage. In addition, no cracking or changes in morphology were observed in the matrix regions.

Modification of the interphase layers is visibly striking and a clear departure from behavior seen in previous tests at the same temperature conditions but substantially lower dose levels [19]. Given previous neutron irradiation tests to $4.6 \mathrm{dpa}$ at 300 and $500^{\circ} \mathrm{C}$ did not show any sign of interphase degradation, increased dose would seem to be responsible for the change. While $\mathrm{SiC}$ has shown to be extremely radiation resistant above its fast neutron critical amorphization temperature $\left(\mathrm{T}_{\mathrm{c}}\right)$ of $\sim 150^{\circ} \mathrm{C}[27,28]$, carbon forms are less resistant. Graphite, for example, readily amorphizes at low temperature [29]. Here, HRTEM and EDS confirmed the transformation of turbostratic carbon in the interphase of the $300^{\circ} \mathrm{C}$ sample to a highly carbon-rich $\mathrm{SiC}$ mixture - a mixture that should be stable to much higher temperatures $\left(1200-1400^{\circ} \mathrm{C}\right)$. Stresses associated with such a shift in phase could certainly contribute to the deterioration of the interphase. In addition, ballistic mixing, 
which has previously been observed in amorphous materials under neutron irradiation, may have contributed to the final interphase structure at low temperature [30].

Though the observed changes in the fiber interphase are significant, the deterioration of the interphase layers is not suspected to be responsible for the large observed drop in flexural strength in the $300^{\circ} \mathrm{C}$ sample [18]. Fiber matrix composites are designed to mitigate brittle fracture; cracks propagating through composites should dissipate at fiber/matrix interfaces. Though deterioration of the interphase could result in reduced proportional limit stresses, such behavior should not result in lowered ultimate strengths of the composite as a whole [31]. Only changes in morphology or phase of the fiber itself should result in decreases in ultimate strength of the composite.

In this study, the only change observed in the microstructures of the SiC fibers themselves was in regards to the secondary phase particle size. We believe that this change may play a role in the observed changes in flexural strength of the fibers, but we cannot rule out the effects of other phenomena that are difficult to quantify via TEM examination alone, including point defect formation, accumulation, and other irradiation-induced synergistic processes such as helium accumulation and precipitation at grain boundaries, though the latter should have only minimal effects due to small levels of helium production [32].

While we have already discussed the potential effects of swelling upon the growth of the secondary phase particles, there is also the matter of the shift of the pockets from turbostratic in the unirradiated condition to amorphous after irradiation. Diffraction patterns (Figure 2) did not indicate any change in fiber phase, but since the fibers are primarily composed of $\mathrm{SiC}$, subtle phase changes of the carbonaceous particles within the fibers are not readily visible through the SAED patterns. Even though HRTEM indicated that these particles were amorphous, EELS was performed on the fibers to see if any further subtle phase shifts were occurring in these secondary phase regions.

Figure 8 shows the results of the EELS tests, with spectra shown at an energy loss region that is relevant to carbon. All fibers showed a strong sigma* $\left(\sigma^{*}\right)$ peak at about 295 $\mathrm{eV}$, but no $\mathrm{pi}^{*}\left(\pi^{*}\right)$ peak was observed at about $285 \mathrm{eV}$. The lack of a $\pi^{*}$ peak would seem to indicate that the carbon in the secondary phase particles is more diamond-like than graphitic or purely amorphous [33], but then again, the lack of this peak may be due to curve smoothening due to the overwhelming presence of $\mathrm{SiC}$, and not just carbon, in the fibers. More importantly however, there is a clear peak in the unirradiated fiber at about $308 \mathrm{eV}$. This peak is less pronounced at 800 and $500^{\circ} \mathrm{C}$ and is nearly gone at $300^{\circ} \mathrm{C}$. While the precise nature of this phase shift is unknown, the fact that the shift is most pronounced in the $300^{\circ} \mathrm{C}$ sample seems to indicate that this shift may be correlated to the growth of the carbonaceous particles and, correspondingly, may be connected to the observed embrittlement in the SiC fibers at this temperature. 


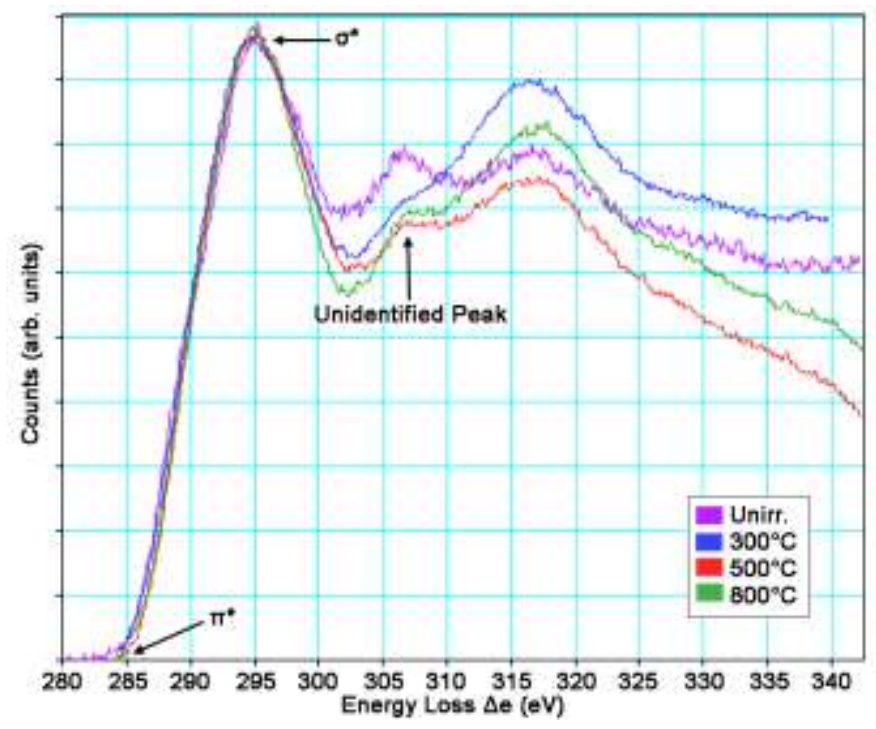

Figure 8. EELS spectra of the unirradiated fiber and the fibers irradiated at 300,500 , and $800^{\circ} \mathrm{C}$.

\section{Conclusions}

A Hi-Nicalon Type S SiC fiber, CVI SiC matrix composite was irradiated to damage levels of $>70 \mathrm{dpa}$ at temperatures of 300,500 , and $800^{\circ} \mathrm{C}$, and decreases in ultimate flexural strength were observed in the lower temperature samples, most notably the sample tested at $300^{\circ} \mathrm{C}$. Microstructural evaluations showed a small but significant change in the size of carbonaceous particles within the fibers irradiated at lower temperatures. Cracking was also observed at the innermost fiber/PyC interfaces, with extensive damage to the entire interphase visible at $300^{\circ} \mathrm{C}$. While electron diffraction did not reveal any change in phase of the SiC fibers, EELS analysis indicated a slight phase shift in the carbonaceous secondary particles present within said fibers, with the greatest shift detected in the fibers irradiated at $300^{\circ} \mathrm{C}$. While further work is needed to fully explain both the nature and reason for the observed changes, growth and phase shift of carbonaceous particles in the fibers are suspected to play a critical role in the embrittlement of the fibers following irradiation.

\section{Acknowledgements}

This research was sponsored by the Office of Fusion Energy Sciences, U.S. Department of Energy under contract DE-AC05-000R22725 with UT-Battelle, LLC. Samples were irradiated in the High Flux Isotope Reactor, an Office of Science User Facility. The TEM characterization utilized ORNL's Shared Research Equipment (ShaRE) User Facility, which is sponsored by the Scientific User Facilities Division, Office of Basic Energy Sciences, U.S. Department of Energy.

\section{References}

[1] Y. Katoh, L.L. Snead, C.H. Henager Jr., A. Hasegawa, A. Kohyama, B. Riccardi, H.Hegeman, J. Nucl. Mater. 367-370 (2007) 659-671.

[2] L.L. Snead, R.H. Jones, A. Kohyama, P. Fenici, J. Nucl. Mater. 233-237 (1996) 26-36. 
[3] A. Kohyama, M. Seki, K. Abe, T. Muroga, H. Matsui, S. Jitsukawa, S. Matsuda, J. Nucl. Mater. 283-287 (2000) 20-27.

[4] R.J. Price, J. Nucl. Mater. 33 (1969) 17-22.

[5] R.J. Price, Nucl. Technol. 35 (1977) 320-336.

[6] T. Noda, M. Fujita, H. Araki, A. Kohyama, Fusion Eng. Des. 61-62 (2002) 711-716.

[7] R.A. Causey, W.R. Wampler, J. Nucl. Mater. 220-222 (1995) 823-826.

[8] P. Fenici, A.J. Frias Rebelo, R.H. Jones, A. Kohyama, L.L. Snead, J. Nucl. Mater. 258-263 (1998) 215-225.

[9] L.L. Snead, T. Nozawa, M. Ferraris, Y. Katoh, R. Shinavski, M. Sawan, J. Nucl. Mater. 417 (2011) 330-339.

[10] T. Nozawa, T. Hinoki, L.L. Snead, Y. Katoh, A. Kohyama, J. Nucl. Mater. 329-333 (2004) 544-548.

[11] Y. Katoh, A. Kohyama, T. Nozawa, M. Sato, J. Nucl. Mater. 329-333 (2004) 587591.

[12] Y. Katoh, T. Nozawa, L.L. Snead, T. Hinoki, J. Nucl. Mater. 367-370 (2007) 774-779.

[13] Y. Katoh, T. Nozawa, L.L. Snead, T. Hinoki, A. Kohyama, Fusion Eng. Des. 81 (2006) 937-944.

[14] Y. Katoh, T. Nozawa, L.L. Snead, K. Ozawa, H. Tanigawa, J. Nucl. Mater. 417 (2011) 400-405.

[15] T. Nozawa, Y. Choi, T. Hinoki, H. Kishimoto, A. Kohyama, H. Tanigawa, IOP Conf. Series: Mater. Sci. Eng. 18 (2011) 162011.

[16] L.L. Snead, Y. Katoh, A. Kohyama, J.L. Bailey, N.L. Vaughn, R.A. Lowden, J. Nucl. Mater. 283-287 (2000) 551-555.

[17] Y. Katoh, K. Ozawa, T. Hinoki, Y. Choi, L.L. Snead, A. Hasegawa, J. Nucl. Mater. 417 (2011) 416-420.

[18] Y. Katoh, T. Nozawa, A.M. Williams, T. Cheng, P. Dou, L.L. Snead, Properties of HiNicalon Type-S CVI SiC Composites Irradiated to 70 dpa at Elevated Temperatures. ORNL/TM-2012/459, September 30, 2012.

[19] G. Newsome, L.L. Snead, T. Hinoki, Y. Katoh, D. Peters, J. Nucl. Mater. 371 (2007) 76-89. [20] D. Gosset, C. Colin, A. Jankowiak, T. Vandenberghe, N. Lochet, J. Am. Ceram. Soc. 96 (2013) 1622-1628.

[21] C. Sauder, J. Lamon, J. Am. Ceram. Soc. 90 (2007) 1146-1156.

[22] L.L. Snead, Y. Katoh, S. Connery, J. Nucl. Mater. 367-370 (2007) 677-684.

[23] C.H. Wu, J.P. Bonal, B. Kryger, J. Nucl. Mater. 208 (1994) 1-7.

[24] L.L. Snead, T.D. Burchell, Y. Katoh, J. Nucl. Mater. 381 (2008) 55-61.

[25] H. Kishimoto, K. Ozawa, S. Kondo, A. Kohyama, Mater. Trans. 46 (2005) 1923-1927.

[26] J.Y. Yan, C.W. Chen, P.C. Fang, K.M. Yin, F.R. Chen, Y. Katoh, A. Kohyama, J.J. Kai, J. Nucl. Mater. 329-333 (2004) 513-517.

[27] L.L. Snead, J.C. Hay, J. Nucl. Mater. 273 (1999) 213-220.

[28] L. L. Snead, T. Nozawa, Y. Katoh, T.-S. Byun, S. Kondo, D.A. Petti, J. Nucl. Mater. 371 (2007) 329-377.

[29] H. Abe, H. Naramoto, A. Iwase, C. Kinoshita, Nucl. Instrum. Methods Phys. Res. B

127/128 (1997) 681-684.

[30] A.T. Motta, C. Lemaignan, J. Nucl. Mater. 195 (1992) 277-285.

[31] A.G. Evans and F.W. Zok, J. Mater. Sci. 29 (1994) 3857-3896.

[32] M.E. Sawan, Y. Katoh, L. Snead, J. Nucl. Mater. 442 (2013) S370-S375. 
[33] J. Robertson, Semicond. Sci. Technol. 18 (2003) S12-S19. 